\title{
Reconstruction on the Whole Design of Teaching Reformation in College English Under the Pattern of "Chinese Wisdom"
}

\author{
Xiaoyan Shang \\ Department of Public Course Teaching \\ Jiangxi Institute of Fashion Technology \\ Nanchang, China 330201
}

\author{
Kuiyou Zhao \\ Office of Academic Affairs \\ Harbin Technician College \\ Harbin, China 150000
}

\begin{abstract}
With the keen observation to capture the national economic reform vane, the overall design of reconstruction is put forward on teaching reformation in College English. The perforation system, "training plus etiquette", is carried out in the school education period; the integrated system which is named "English subjects plus general ability" is used into the classroom teaching; the occupational system "ability plus professionalism" is used into practical teaching stage; during the teaching evaluation stage, the assessment system "ability plus behavior" is implemented.
\end{abstract}

Keywords-Chinese wisdom; teaching reformation; overall design; reconstruction

\section{INTRODUCTION}

The "Made in China 2025" plan is the watershed of vocational education in China. It is the "Made in China" plan before 2015 and the development of "Intelligent Manufacturing in China" after 2015. With the development of our country from the "Made in China" plan to the "Intelligent Manufacturing in China" plan, the original goal of higher education to train single professional and skilled personnel can no longer meet the requirements of talent training of the times. It is necessary to design and reconstruct the teaching reform of colleges according to the model of "Intelligent Manufacturing in China"[1].

\section{THE REASON OF THE RECONSTRUCTION}

The world has entered the fourth industrial revolution nowadays, that is, the period of the intelligent revolution (the first three industrial revolutions are the steam engine revolution, the electric power revolution, and the information revolution), and the new generation of information technology and manufacturing are deeply integrated. It is triggering a far-reaching industrial revolution to form new modes of production, industrial forms, business models and economic growth points. All countries are increasing the intensity of scientific technological innovation for promoting the deep integration of manufacturing and information technology, and promoting 3D printing [2]. Mobile for networking, cloud computing, big data bioengineering, new energy, new materials and other areas have made new breakthroughs.

We outsource labor and outsourcing owners support technology in the "Made in China" period. And in the period of "Intelligent Manufacturing in China", we produced labor force and technology to create our own brand. Higher education should go out, take the initiative to contact the construction enterprises of "Belt and Road" project. It also need train professional talent echelons according to the specifications and standards of the talents needed by the enterprises, and should meet the requirements of the followup projects of the docking projects. The orientation of running a school and the training specifications of talents should be reconstructed. We should do a good job in the construction of English curriculum system, continuously improve the level of talent training to cultivate technical English talents with high technology level, initiative and innovative ability, which makes it better serve the local economic and social development [3]. The "Made in China 2025 " plan puts forward the basic policy of "innovationdriven, quality-oriented, green development, structural optimization, talent oriented" to achieve the strategic goal of manufacturing power.

\section{THE RECONSTRUCTION OF CONTENT}

"Military Training +Etiquette" should be implemented during entering the school education. The English proficiency of students in college is uneven. They all have some problems more or less, just like a small tree. It is not realistic for such trees to be transported to school and processed into finished products at once, because if we arm the curved, branched trees with knowledge and skills, and wait for them to succeed in their studies. They are bound to have problems at work because of their own problems. And sometimes the more skillful they are, the more harmful they will be to society. Therefore, sharpening the axe will not interfere with the cutting of firewood. Students must first pass the military training education and the etiquette education before the formal class. The instructors were invited to watch the American movies, Enders Game, and were familiar with the relevant commands and behaviors of the teachers and students in the film. When instructors, 
leaders, and teachers are arriving, the monitor or group leader or anyone must say, "Attention", then the students stand at attention immediately. Instructors, leaders, and teachers must say, "At ease", students with their feet apart and their hands resting behind them, say "Sir yes Sir" if yes, and "Sir no sir" if not. The instructor then asks the students to watch the film to familiarize the students with the relevant commands and movements. In order to train the relevant commands and behaviors in the actual military training, the instructors and students can tell the students that these commands and behaviors should be carried out not only the whole school period, but also the practice period and the working period of the students. Special note: the rest of the military training according to the arrangements of the instructor, this content is only a small episode of the entire military training [4].

Teachers only pay attention to inculcating professional knowledge and training their skills in the period of "Made in China", but they have no general knowledge ability. The students embody the typical characteristics of "tool man" in this way. Therefore, it is suggested that the general knowledge ability should be incorporated into the specialty English teaching content through the teaching and research activities in the teaching and research departments and the collective preparation of classes. The teaching design of the general knowledge ability should be reflected in the teaching plan, which gradually infiltrates several of abilities in order to train talents for "Intelligent Manufacturing in China", such as the language expression ability, self-study ability, adaptive ability, moral care ability, theory to practice ability, communication and coordination ability, independent thinking ability, problem-solving ability, creative ability, etc.

Because the content of basic English course emphasizes on the knowledge content, teachers are apt to fall into the strange circle of "knowledge inculcation" in the teaching process. It is one of the reasons why students are tired of learning by introducing them into the learning atmosphere of "middle school classroom". Therefore, teachers should "look for the ability from the knowledge teaching material" and design the classroom teaching which is guided by the ability. The concrete operation steps are as follows: (1) The knowledge teaching material of each course should be redeveloped in every semester. Make several projects and choose the topics or topics you want to study according to the students' interests. (2) Students should be encouraged to go to the library to collect data and start research. (3) Students organize the materials and write an operation report. (4) Every student introduce his research results on the stage, then the others students can ask questions and students in front of the classroom can answer the questions.

The general knowledge system of elective courses is that the design of elective courses should be based on the general courses so that students can know more about humanities and social sciences. At present, some colleges open optional courses according to their teachers and professional requirements. The elective course should serve for the cultivation of general knowledge, and it is suggested that general education should be offered. Secondly, we must break through the formal classroom teaching mode in the teaching mode. It is better to adopt the television variety show, something like Chinese Poems Congress, Reading Club, Toastmasters, and Overview Society and so on. For example, Instead of talking about the meaning of a speech, the type of speech, the strategy in the English lecture class, the teacher should ask students to check the lecture content through the library or the Internet, watch celebrity research videos, and then assign a speech topic at a time. The teacher's task is to guide students to speak in class, and then teachers and students to make comments each other. It is best to develop competition between class and class, and between department and department, so as to mobilize students to look up materials in the library during morning and evening self-study to surpass themselves every time.

The vocational system of "ability type + professional accomplishment" will be used in the stage of English practical teaching. The system of "ability type + professional accomplishment" is to infiltrate professional accomplishment into the process of English teaching. Teachers, English practical training, should prepare lessons in cooperation with teachers teaching the course named Vocational Guidance. Teachers of English courses and guide teachers should carry out the redevelopment of the teaching materials of Vocational Guidance. Bilingual teaching should be carried out. The new textbook should develop the knowledge teaching content into the ability type and the behavior type teaching content, and accords with the practical training process. The students are requested to embody the profession behavior and the standard everywhere in the practice training. It is very important to diligently train the students' responsibility consciousness. The research found: the skillful person who doesn't have the responsibility in the enterprise cannot serve for the society and the country. Therefore, colleges should try to cultivate students' responsibility consciousness [5].

The "ability + behavior" assessment system will be implemented in the teaching evaluation stage. It means replacing the knowledge assessment method on the paper with the ability and behavior assessment system. The students don't have to attend the final examination, they can take part in other kinds of examination, such as the standard quiz, the match quiz and the performance quiz etc. Some of students can finish the standard quiz in every class for solving the problem of plagiarism of students' examination, which effectively avoids the realistic problem that students cannot memorize more things at the end of each class. This short, flat and fast assessment method effectively solves the phenomenon of "temporary cramming" in the final period of the students. In addition, instead of letting students to memorize knowledge, teachers should change knowledge into behavior to assess students.

\section{CONCLUSION}

It is necessary to design and reconstruct the teaching reform of colleges in the period of "Chinese intellectual creation" according to the national economic vane, which put forward that the foundation of specialty teaching should be used to strengthen the teaching of culture course for students' lifelong. The college should strengthen general 
citizen and the speculative citizen who have the rich interest, the personality integrity and the sane mind with general knowledge ability. Only when the education returns to its true nature can it sow a behavior, reap a habit. The fate of students, in fact, is the fate of our colleges.

\section{REFERENCES}

[1] Chen Xinyuan. The Direction and Strategy of English Teaching Reform in China from the Perspective of Global Education [J]. Teaching and Management, 2017(06): 108-110.

[2] Zhou Jianxin. An Empirical Study on the Effect of the Process Assessment of the Humanities General course: an Analysis based on the "Selected English Poems" Process Test in the course of Humanistic General Education [J].Journal of Nanchang normal University, 2016(04): 69-73.

[3] Li Xiaoxuan. A Probe into College English Teaching Theory and Teaching Reform Strategies: a Review of Modern College English Teaching Research: theory, methods and Strategies [J]. Research on Educational Development, 2016 (03): 86.

[4] Wang Jing. Research on General Education Model of higher Vocational Colleges in China [D]. Wuhan University, 2013.

[5] Liu Lingyu. A probe into the Teaching of "feedback" in College English General Education and Culture [J]. English Plaza (Academic Studies), 2013 (08): 92-93. 